University of Nebraska - Lincoln

DigitalCommons@University of Nebraska - Lincoln

Entomology Papers from Other Sources

Entomology Collections, Miscellaneous

2006

Cowpea weevil flights to a point source of female sex pheromone: analyses of flight tracks at three wind speeds

L. P. S. Kuenen

USDA-ARS

H. C. Rowe

University of California

Follow this and additional works at: https://digitalcommons.unl.edu/entomologyother

Part of the Entomology Commons

Kuenen, L. P. S. and Rowe, H. C., "Cowpea weevil flights to a point source of female sex pheromone: analyses of flight tracks at three wind speeds" (2006). Entomology Papers from Other Sources. 17.

https://digitalcommons.unl.edu/entomologyother/17

This Article is brought to you for free and open access by the Entomology Collections, Miscellaneous at DigitalCommons@University of Nebraska - Lincoln. It has been accepted for inclusion in Entomology Papers from Other Sources by an authorized administrator of DigitalCommons@University of Nebraska - Lincoln. 


\title{
Cowpea weevil flights to a point source of female sex pheromone: analyses of flight tracks at three wind speeds
}

\author{
L.P. S. K UENEN ${ }^{1}$ and H. C. R O W E ${ }^{2}$ \\ ${ }^{1}$ USDA, ARS, Crop Protection and Quality, Parlier, California, U.S.A. and ${ }^{2}$ Department of Vegetable Crops, University of \\ California, Davis, California, U.S.A.
}

\begin{abstract}
Two-day-old male cowpea weevils, Callosobruchus maculatus, fly upwind to a point source of female sex pheromone at three wind speeds. All beetles initiating flight along the pheromone plume make contact with the pheromone source. Analysis of digitized flight tracks indicates that C. maculatus males respond similarly to moths tested at several wind speeds. Beetles' mean net upwind speeds and speeds along their track are similar $(P>0.05)$ across wind speeds, whereas airspeeds increase $(P<0.01)$ with increasing wind speed. Beetles adjust their course angles to fly more directly upwind in higher wind speeds, whereas track angles are almost identical at each wind speed. The zigzag flight paths are generally narrow compared with most moth flight tracks and interturn distances are similar $(P>0.05)$ at the wind speeds employed. The frequency of these counterturns across the wind line is almost constant regardless of wind speed, and there is little variation between individuals. The upwind flight tracks are more directly upwind than those typically seen for male moths flying upwind toward sex pheromone sources. Male moths typically produce a bimodal distribution of track angles to the left and right of the windline, whereas C. maculatus males' track angles are centred about $0^{\circ}$. Preliminary examination of two other beetle species indicates that they fly upwind in a similar fashion.
\end{abstract}

Key words. Callosobruchus maculatus, cowpea weevil, flight, orientation, sex pheromone, wind speed, wind tunnel.

\section{Introduction}

Computer-aided analyses of upwind flight patterns of male moths toward sex pheromone sources have been in progress for approximately 20 years, but the flight patterns of beetles to pheromone sources have been largely ignored, even though sex and aggregation pheromones of several species have been known for some time. Fadamiro \& Wyatt (1995) determined optimal time and environmental conditions for flight initiation of adult Prostephanus truncatus (the larger grain borer); subsequently, Fadamiro (1996, 1997) used these parameters to establish flight assays for the effects

Correspondence: L. P. S. Kuenen, USDA, ARS, Crop Protection and Quality, 9611 S. Riverbend Avenue, Parlier, CA 93648, U.S.A. Tel.: +1559 596 2762; fax: +1559 596 2721; e-mail: bkuenen@fresno.ars.usda.gov of wind speed, pheromone concentration and starvation on the number and duration of male and female $P$. truncatus flights to the aggregation pheromone, which had been identified with the aid of a walking bioassay (Cork et al., 1991). Choudhury \& Kennedy (1980) employed flight responses of the smaller European elm bark beetle (Scolytus multistriatus) in a wind tunnel to address questions of anemotaxis vs. chemotaxis and phototaxis vs. geotaxis. Bartelt et al. (1990) employed flight response bioassays during the identification process of aggregation pheromones of Carpophilus hemipterus comparing the number of beetle 'hits' on a target disk behind which putative pheromone blends were emitted. Phillips et al. (1996) employed flight assays (the upwind flight distances and response numbers in a wind tunnel) in the elucidation the female sex pheromone of the cowpea weevil, Callosobruchus maculatus (F.), a cosmopolitan pest of pulses (grain legumes) (Food \& Agriculture Organization, 1970). 
Lextrait et al. (1994) demonstrated male C. maculatus' upwind walking responses to female sex pheromone in a glass-tube assay chamber but, to the authors' knowledge, there is no analysis of the flight tracks of any beetle species to determine their actual ground speeds, airspeeds or steering responses. In the present study, male cowpea weevils fly upwind in generally zigzag paths along the axes of pheromone plumes. Test beetles steer upwind close to the windline, and adjust their course angles and airspeeds to maintain constant track angles and ground speeds at three wind speeds.

\section{Materials and methods}

Insects

Cowpea weevils, C. maculatus, were reared on cowpeas/ black-eyed peas [Vigna unguiculata (L.) Walp.] in 4-L culture jars by placing approximately 400 mixed-sex adult beetles in a clean jar containing $1 \mathrm{~kg}$ of organically grown cowpeas. New peas were infested weekly and were maintained in an incubator at $26 \pm 1{ }^{\circ} \mathrm{C}$, at approximately $60 \%$ relative humidity $(\mathrm{RH})$ under an LD $16: 8 \mathrm{~h}$ photoperiod. The beetles used to start this culture were collected in November 2000, from chick peas/garbanzo beans in a storage facility near Patterson, California (voucher specimens have been deposited with the insect museum at the University of Riverside, California). Male beetles used for flight tests were collected from a culture jar, with emerging beetles, by screening out all newly-emerged adults at 2-h intervals, and males were separated from females by the external markings noted by Raina (1970). Males were held for 2 days in empty 4-L jars in the incubator described above.

\section{Pheromone}

Female sex pheromone was collected as volatiles from newly-emerged females. Cowpeas containing C. maculatus pupae were placed singly in 4-mL shell vials with foam stoppers and checked daily for emergence of adults. On the day of their emergence, adult females were transferred to hexane-rinsed vials containing a fresh cowpea and a $0.5 \times 3-\mathrm{cm}$ strip of Whatman \#1 filter paper (Whatman Plc, U.K.) (Phillips et al., 1996; Shu et al., 1996). After 5 days, females and peas were removed and discarded, vial walls were rinsed three times with high-performance liquid chromatography grade hexane (approximately $1 \mathrm{~mL}$ ) and the filter paper strips were extracted in this rinse hexane. The vial and filter paper were extracted for 2-3 min and then the hexane extract was decanted into a holding flask. In this fashion, the female sex pheromone volatiles (plus cowpea volatiles) were collected from each vial in increments of 5 female-day equivalents (FDEs). This procedure continued until approximately 400 FDEs of extract were accumulated. The total volume of the extract was reduced, with a gentle stream of helium, to approximately 0.25 FDE of sex pheromone (plus cowpea volatiles) per $\mu \mathrm{L}$ of solution.

A pheromone source was prepared by pipetting $25 \mathrm{FDE}$ $(100 \mu \mathrm{L})$ onto a $2 \times 5$-cm piece of Whatman \#1 filter paper, which was air-dried in a fume hood for $1 \mathrm{~min}$. The filter paper was then inserted into a $100-\mathrm{mL}$, silanized-glass odour-delivery jar (Fig. 1). Charcoal-filtered compressed air carried the pheromone through Teflon tubing to the odour-release platform (Fig. 1). A $9 \times 19$-mm rubber septum was placed $5 \mathrm{~cm}$ directly upwind of the pheromone exit to produce a turbulent plume structure (Marsh et al., 1978); tests with $\mathrm{TiCl}_{4}$-generated smoke emitted from the odourdelivery tube indicated no apparent differences in plume structure at the wind speeds used. The Teflon odour-delivery tube and the aluminium receiving plate were hexanerinsed before each use. The wind tunnel has a $98 \times 98 \times 240$-cm working section, open at the downwind end with air pushed through the tunnel by a variable speed fan (Fig. 2).

\section{Experiments}

For tests of male cowpea weevil flight responses in different wind speeds, beetles were tested in winds of 47, 70 and $93 \mathrm{~cm} \mathrm{~s}^{-1}$ as measured with a Kurz ${ }^{\circledR}$ hot-wire (Kurz

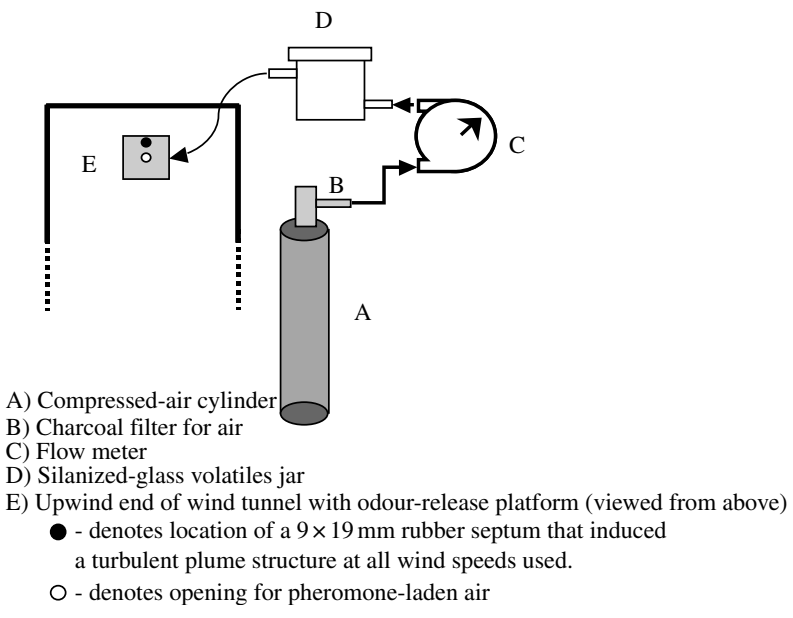

Fig. 1. Diagrammatic representation of odour-delivery system for cowpea weevil sex pheromone for wind tunnel tests. Charcoalfiltered compressed air was metered through the odour-delivery jar at $360 \mathrm{~mL} \mathrm{~min}^{-1}$ producing a $70 \mathrm{~cm} \mathrm{~s}^{-1}$ pheromone-laden air flow through a Teflon tube (inner diameter $3.3 \mathrm{~mm}$; outer diameter $3.5 \mathrm{~mm}$ ) that was routed to a $15-\mathrm{cm}$ square aluminium plate with $15 \mathrm{~cm}$-long $\times 2.5 \mathrm{~cm}$-wide legs; all aluminium surfaces were $0.7 \mathrm{~mm}$ in thickness. The stand was axially centred in the tunnel $26 \mathrm{~cm}$ from the upwind end with platform surfaces aligned with the wind to minimize turbulence. A $4.5-\mathrm{mm}$ hole was drilled through the centre of the aluminium plate through which a $5-\mathrm{mm}$ piece of 4.5-mm outer diameter Teflon tubing was inserted; this tube was slightly flared on the bottom to receive the Teflon tube carrying the pheromone-laden air. 


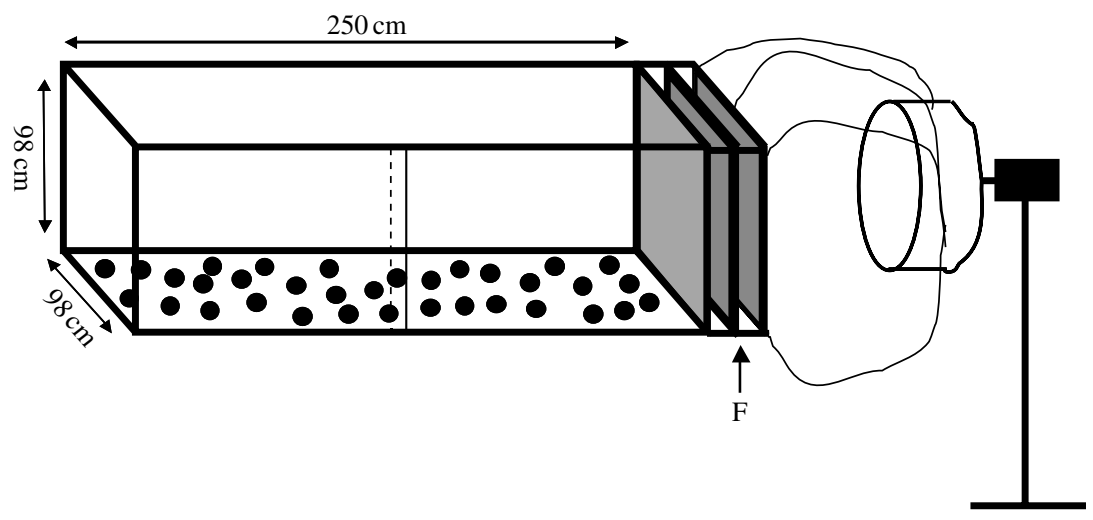

Fig. 2. Diagrammatic representation of the wind tunnel. The tunnel is constructed of 6-mm thick Plexiglas ${ }^{\circledR}$ panels affixed along their long edges to 6-mm thick aluminium rails bent $90^{\circ}$ in cross section, and to welded box-section aluminium exterior frames at each end. Tunnel access is through the downwind end or through one side composed of two 130-cm long door panels that slide parallel on closely apposed rails. Wind is provided by a variable speed DC-motor/fan with a rectified voltage-controller; the fan blades are surrounded by a $30 \times 50$-cm diameter aluminium sheet-metal duct. Air is ducted to the upwind end of the tunnel by a flexible, polyethylene-sheeting $(0.3 \mathrm{~mm}$ in thickness $)$ tube that is attached to the fan duct and the tunnel's upwind aluminium frame. Fan-driven air passes through three layers of charcoal-andzeolite-impregnated filter material (Quality Filters, Robertsdale, Alabama) that are held in individual aluminium frames (shown here in expanded view; 'F'). These filter layers provide air cleaning (Heath \& Manukian, 1992) and reduce large-scale air turbulence; air passing through the tunnel is recirculated through the assay room. Point-source plumes flowed horizontally straight down the tunnel with little spread, as visualized by smoke plumes. Test insects flew along pheromone plumes that were $15 \mathrm{~cm}$ above the tunnel floor, which had a 10 -cm diameter red-dot pattern randomly distributed over a white floor covering (approximately $25 \%$ of the floor area comprised red dots). Lighting in the assay room was from above by two 96-W fluorescent tubes (120 Hz; paired 240-cm long tubes) orientated longitudinally with respect to the tunnel and positioned directly above the working section. These lights were supplemented by six clear 25 -W incandescent bulbs, three spaced $82 \mathrm{~cm}$ apart in parallel rows, $20 \mathrm{~cm}$ from both sides of the fluorescent tubes. Light intensity at flight height $(15 \mathrm{~cm})$ was approximately $1.90 \mathrm{~W} \mathrm{~m}^{-2}$ from above, $0.77 \mathrm{~W} \mathrm{~m}^{-2}$ from the sides and $0.62 \mathrm{~W} \mathrm{~m}^{-2}$ from the floor (converted from lux, as measured by a FisherBrand ${ }^{\mathrm{TM}}$ light meter, model 06-662-64 (Fisher Scientific, Friendswood, Texas); Young et al., 1987).

Instruments, Monterey, California) anemometer (model 491; calibrated by timing smoke puffs through a $1.5-\mathrm{m}$ section of the tunnel). During tests, the flight tunnel room conditions were maintained at $27-29{ }^{\circ} \mathrm{C}$ and $45-60 \% \mathrm{RH}$. Beetles were tested during hours $9-11$ of photophase.

Jars containing unfed, 2-day-old males were moved to the wind tunnel $60 \mathrm{~min}$ before flight tests were conducted. After $30 \mathrm{~min}$, males were placed singly into clean $20 \times 50-\mathrm{mm}$ glass tubes closed at each end with a foam rubber plug and placed on the tunnel floor for $\geq 15$ min before male release. A tube with a quiescent male was opened and then gently tapped to displace the beetle onto a filter paper disk $(9 \mathrm{~cm}$ in diameter) taped to the top of a $12.5 \mathrm{~cm}$-high release platform (white polyvinyl-chloride plastic cylinder, $5 \mathrm{~cm}$ in diameter) positioned $160 \mathrm{~cm}$ straight downwind of the pheromone platform. Beetles not initiating flight within 3 min were discarded. Each beetle was tested only once.

\section{Flight track recording and analysis}

Upwind flight tracks of beetles were recorded in plan view from above with a Sony DCR-VX2000 digital video camera/recorder (Sony Corp., Japan). The camera was orientated vertically above the tunnel, providing a $50 \times 80-\mathrm{cm}$ field of view at $15 \mathrm{~cm}$ high, with its upwind end $48 \mathrm{~cm}$ from the pheromone source. Flight-track records were transferred to a Sony Vaio ${ }^{\mathrm{TM}}$ computer using Sony DV-gate ${ }^{\circledR}$ software. Beetle flight tracks were subsequently digitized on the computer monitor with Mantid $32^{\circledR}$ software (Synceros Inc., Ithaca, New York). To obtain mean course angles, track angles, drift angles, airspeeds and ground speeds, calculations were based on the triangle of velocities method (Kennedy, 1940; Marsh et al., 1978). Data files [consecutive (1/30 s) $x, y$ coordinate pairs for each flight track] were analysed with a computer program developed by Kuenen \& Baker (1982); see also Charlton et al. (1993); Kuenen \& Cardé (1993, 1994) for calculation of the beetle movement parameters along each flight-track vector (track segment between consecutive beetle locations). In the present study, the mean track angle was calculated for an entire track by calculating the mean ' $x$ ' and ' $y$ ' displacements from all the vectors of a given track, yielding a mean resultant track vector. This procedure was followed to avoid the error inherent in calculating arithmetic means directly from angle measurements (Batschelet, 1981), especially when vector lengths are not equal, as is typical during the dynamic free flight (Willis \& Arbas, 1998) of these male beetles. Subsequent calculations and analyses of movement and steering components of males along their flight tracks were also based on this resultant vector and the three wind speed vectors (Kuenen \& Cardé, 1993, 1994). A program subroutine was written to determine the turn apices and calculate interturn reversal 
distances and durations (inverse of turns $\mathrm{s}^{-1}$ ). Turn apices were defined as the points where males changed direction across the wind line (Kuenen \& Cardé, 1993, 1994) and interturn reversal distances were taken as the lateral displacement between the apices of consecutive turns. Frequency histograms were also constructed of track, course and drift angles calculated for all individual track vectors for comparisons among upwind flights at the three wind speeds tested.

\section{Statistical analysis}

Tests were conducted in a randomized complete block design with one beetle flight per wind-speed treatment per replicate; tests were conducted over the course of 18 days. No data transformations were necessary, as indicated by Bartlett's test for homogeneity of variances (Sokal \& Rohlf, 1981). Analyses of variance and mean separation tests were conducted with PROC GLM AND Tukey's test in SAS (SAS, 2001). Replicates $(n=2)$ that contained beetle flights of more than $12 \mathrm{~s}$ duration were discarded because these long flights were the result of frequent excursions out of the pheromone plume, and the beetles' apparent initiation of casting (Kennedy, 1983) before recontacting the plume. Twenty-five replicates of beetle flights were analysed.

\section{Results}

All cowpea weevil males initiating flight along the pheromone plume made contact with the pheromone source. These beetles flew along the pheromone plume in a zigzag manner (Fig. 3A,B) akin to that recorded from male moths as they fly toward sex pheromone sources (Marsh et al., 1978; Kuenen \& Baker, 1982; Willis \& Cardé, 1990; Charlton et al., 1993; Kuenen \& Cardé, 1993, 1994) and as verbally described for the larger grain borer beetle (Fadamiro \& Wyatt, 1995). However, a small majority (43 of 75) of the cowpea weevil males had flights with relatively long straight segments orientated nearly directly upwind, punctuated by fairly rapid (short duration) turns across the windline (Fig. 3C-F); this is quantitatively manifested by the high number of track legs that are orientated within $5^{\circ}$ of the wind line (Fig. 5A).

The mean ground speeds and net upwind speeds of the male beetles were similar $(P>0.05)$ among the three wind speeds tested (Fig. 4A); however, at different wind speeds, the mean air speed of the beetles increased linearly with increased wind speed $(P<0.01$; Fig. 4A). Males' mean track angles were the same among the three wind speeds $(P>0.05$; Fig. 4B), and these track angles were centred about $0^{\circ}$ degrees (directly upwind; Fig. 5A) (i.e. the category of $\pm 5^{\circ}$ from upwind had the highest number of track vectors at each wind speed). Beetles steered their courses narrowly upwind and closer to the wind line at higher wind speeds $(P<0.05$; Fig. 4B). As the beetles steered more upwind at higher wind speeds, their drift angles increased, although not significantly $(P>0.05$; Fig. $4 \mathrm{~B})$, in order to maintain similar $(P>0.05)$ mean track angles (Fig. 4B). The lateral extent of the cross-wind flights, as measured by the mean interturn reversal distances, were $<7 \mathrm{~cm}$ at all three wind speeds $(P>0.05$; Fig. $4 \mathrm{C})$. Additionally, the frequency of these turns (turns $\mathrm{s}^{-1}$; Fig. 4C) remained almost constant at 3.6 turns s$^{-1}$, regardless of the wind speed, and the variability among these turn rates was very low (range of means $\pm 1 \mathrm{SE}, 3.55-3.65 \pm 0.18-0.31$ ).

\section{Discussion}

This is the first detailed analysis of male beetle flight tracks to female sex pheromone (plus cowpea volatiles). The
(A)

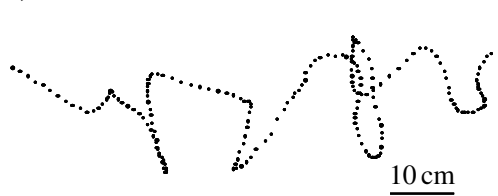

(C)

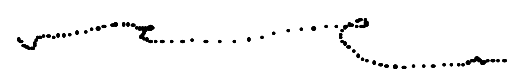

(E)

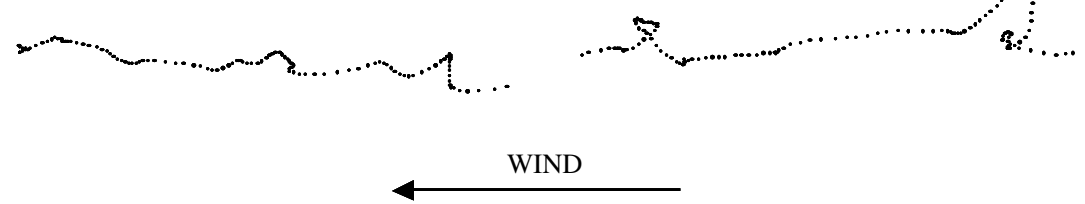

(B)

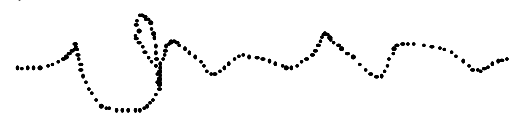

(D)

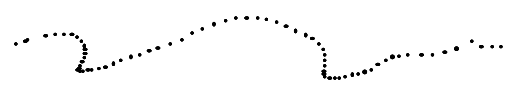

(F)

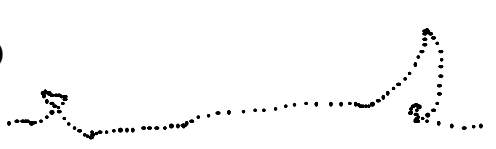

Fig. 3. Representative flight tracks of male Callosobruchus maculatus flying upwind toward a sex pheromone source (25 FDE); wind is from the right at $70 \mathrm{~cm} \mathrm{~s}^{-1}$. (A,B) Zigzag tracks similar to those reported for male moths. (C-F) Tracks showing the more upwind nature exhibited by the majority of C. maculatus males in this study.

C 2006 The Authors Journal compilation (c) 2006 The Royal Entomological Society, Physiological Entomology, 31, 103-109 
(A)

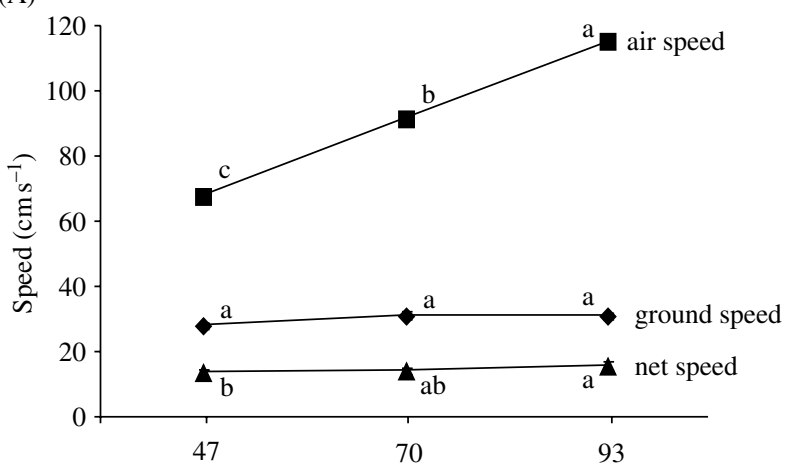

(B)

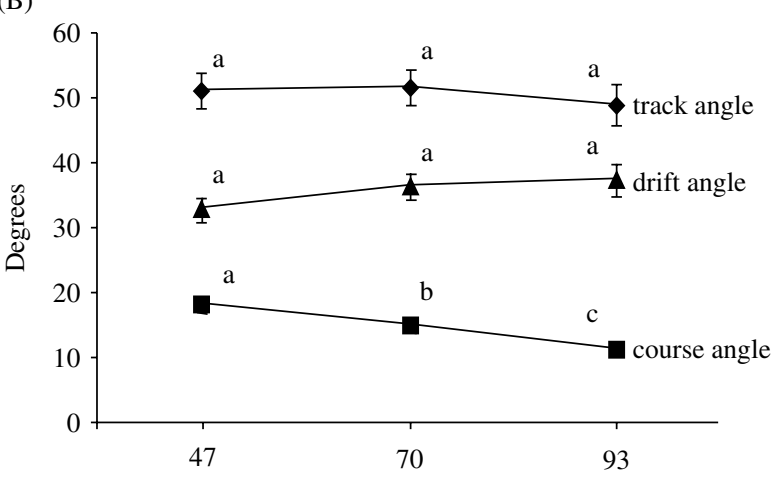

(C)

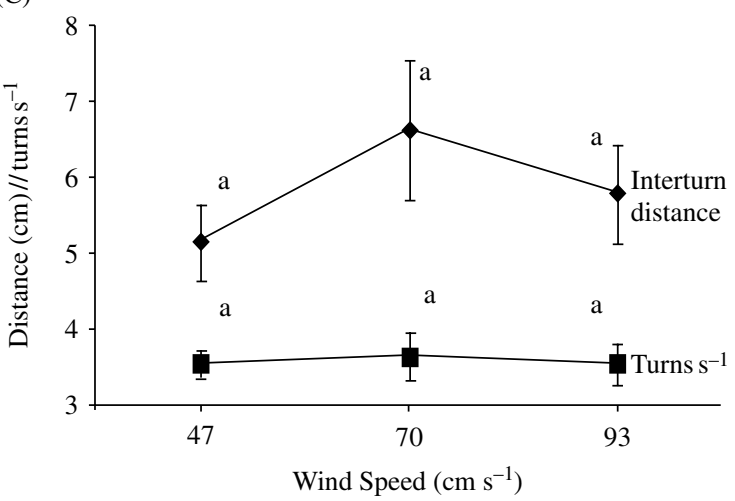

Fig. 4. Mean $\pm 1 \mathrm{SE} \quad(n=25) \quad$ of selected parameters of Callosobruchus maculatus male flight tracks during upwind flight toward a sex pheromone source at 47,70 and $93 \mathrm{~cm} \mathrm{~s}^{-1}$ wind speeds. (A) Mean air speeds, ground speeds and net upwind speeds. (B) Mean track angles, drift angles and course angles. (C) Mean interturn reversal distances and mean turn rates. Means along each line with no letters in common are significantly different (Tukey's test $P<0.05$ ).

maintenance of constant track angles and ground speeds when flying upwind into three wind speeds indicates that, similar to the beetle P. truncatus (Fadamiro, 1995, 1997), C. maculatus males employ an optomotor anemotaxis (Kennedy, 1940) to fly toward and locate an attractant/ odour source. The cerambycid Phoracantha semipunctata (Barata \& Araujo, 2001) also appears to employ an optomotor anemotaxis to fly upwind toward food volatiles.
In wind tunnel assays, the flights of various male moths (Marsh et al., 1978; Cardé \& Hagaman, 1979; Kuenen \& Baker, 1982; Willis \& Arbas, 1991; Kuenen et al., 1994; Mafra-Neto \& Cardé, 1994; Vickers \& Baker, 1997) or male and female moths (Haynes \& Baker, 1989; Willis \& Arbas, 1991) differ only in small detail. The basic flight pattern is an alternating left-right-left zigzag across the windline while progressing upwind toward the odour source. These reversals across the windline are an integral defining part of the zigzagging flight of these various species as they fly upwind toward an odour source (Arbas et al., 1993). In addition, the existence of an apparent endogenous, central nervous system counter-turn generator driving the fairly regular cadence of crosswind turns is also an integral defining part of this flight behaviour (Baker, 1989, 1990). Callosobruchus maculatus males exhibited very regular crosswind turn intervals (Figs 3 and 4) when flying upwind toward a pheromone source and, as in moths, it was independent of wind speed (Marsh et al., 1978; Cardé \& Hagaman, 1979; Willis \& Arbas, 1991).

The cross-wind nature of the interturn reversals leads to a distribution of track angles for moths that is typically bimodal, left and right of $0^{\circ}$ (upwind; Willis \& Baker, 1987; Kuenen \& Cardé, 1993). Male cowpea weevil flights toward a source of female sex pheromone are also zigzag paths along the pheromone plume with adjustments to their course angles and air speeds while flying upwind in three wind speeds. However, the distribution of the beetles' track angles is distributed about $0^{\circ}$ and their course angles are more narrowly distributed about $0^{\circ}$. This more upwind bias of the tracks is also evident when the actual flight paths are examined (Fig. 3C-F). A similar, more upwind orientation of interturn track-legs is also noted for male and female A. transitella (Haynes \& Baker, 1989); nonetheless, in both A. transitella and C. maculatus, cross-wind reversals still occur on a regular basis.

Callosobruchus maculatus' adjustments to their course angles and airspeeds are similar to those exhibited by moths, as measured approximately by Fadamiro (1996). However, by contrast to synchronous flight muscle systems in moths, these beetles employ asynchronous flight muscles. Drosophila hydei, also with asynchronous muscles, rotates its body to a more horizontal position at higher wind speeds to maintain a hovering position (David, 1978), whereas Lymantria dispar and Sparganothis sulphureana males increase their wing beat frequencies as well as rotating their bodies more horizontally to fly at higher airspeeds (Kuenen, unpublished data). Further analyses of the flight behaviour of C. maculatus (and other insects with asynchronous flight muscles) in response to various pheromone dosages and plume structures should yield greater insight into the overall mechanisms employed by insects to fly upwind toward an odour/attractant source.

Beetles present us with several additional opportunities to further our understanding of the mechanisms employed in odour-source location. Some beetle spp., such as C. maculatus, employ a sex pheromone for mate location, whereas others, such as Rhyzopertha dominica (the lesser 
(A)
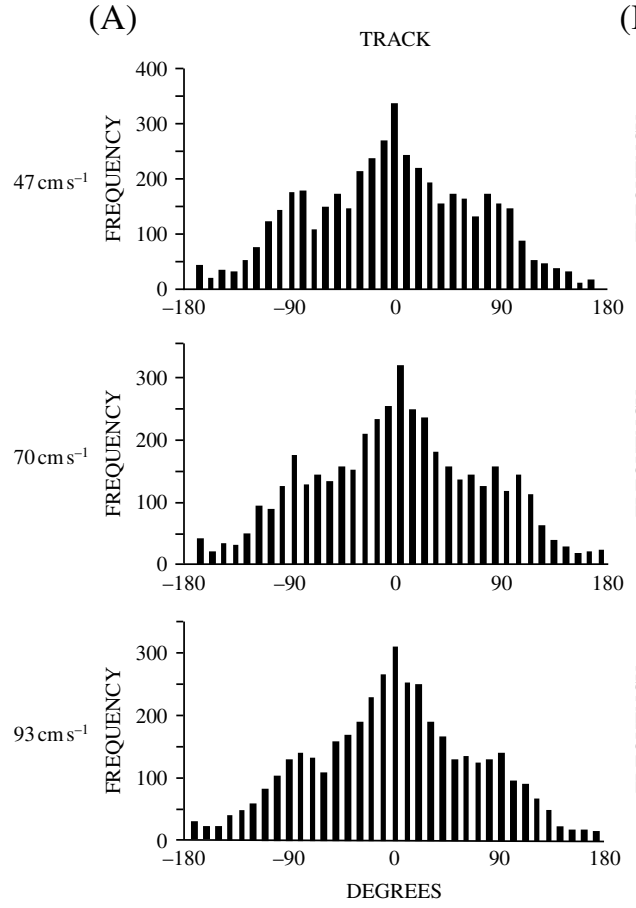

(B)
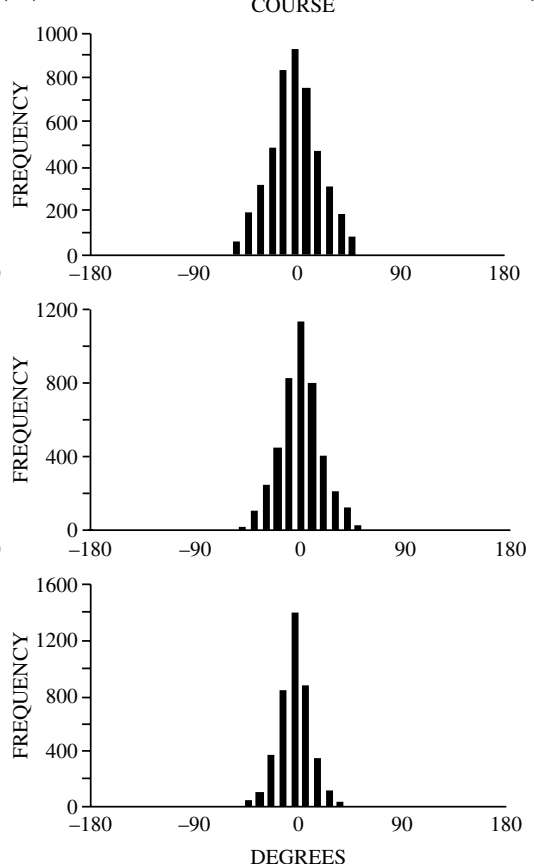

(C)
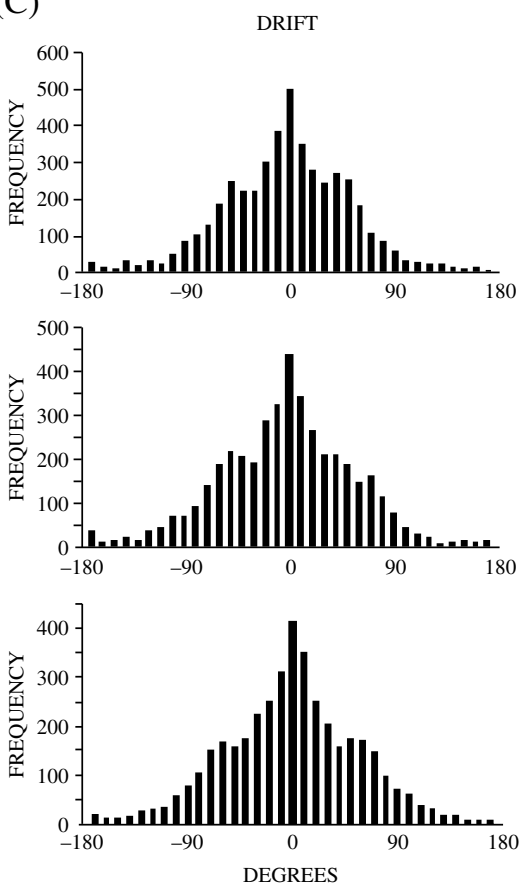

Fig. 5. Frequency distribution histograms of flight track angles, sampled every $1 / 30 \mathrm{~s}$ of Callosobruchus maculatus' upwind flight to sex pheromone at 47, 70 and $93 \mathrm{~cm} \mathrm{~s}^{-1}$ wind speeds; $n=25$ flight tracks for each wind speed. (A) Track angles. (B) Course angles. (C) Drift angles. Zero degrees is due upwind, whereas $\pm 180^{\circ}$ is downwind.

grain borer), employ a male-released aggregation pheromone (Williams et al., 1981) that attracts both sexes. Another variation is presented by Carpophilus hemipterus (the dried fruit beetle), which employs a male-released aggregation pheromone (Bartelt et al., 1990) that is active only in the presence of food volatiles, which in turn are also strong attractants in their own right. Males and females of these beetle species also fly upwind in an apparent zigzag fashion (Kuenen, unpublished data).

In conclusion, cowpea weevil males fly in generally zigzag paths upwind along the female sex pheromone plume to make contact with the pheromone emission source, in a manner similar to moths flying upwind to sex pheromone or food odours. The current analysis of C. maculatus' upwind flight toward a sex pheromone source supports the general model for odour-mediated optomotor anemotaxis that has been demonstrated extensively in moths.

\section{References}

Arbas, E.A., Willis, M.A. \& Kanzaki, R. (1993) Organization of goal-oriented locomotion: pheromone-modulated flight behavior of moths. Biological Neural Networks in Invertebrate Neuroethology and Robotics (ed. by R. D. Beer, R. F. Ritzmann and T. McKenna), pp. 159-198. Academic Press, San Diego, California.
Baker, T.C. (1989) Pheromones and flight behavior. Insect Flight (ed. by G. J. Goldsworthy and C. H. Wheeler), pp. 231-255. CRC Press Inc., Boca Raton, Florida.

Baker, T.C. (1990) Upwind flight and casting flight: complimentary phasic and tonic systems used for location of sex pheromone sources by male moths. Tenth International Symposium on Olfaction and Taste (ed. by K. B. Døving), pp. 18-25, Graphic Communication System A/S, Oslo, Norway.

Barata, E.N. \& Araujo, J. (2001) Olfactory orientation responses of the eucalyptus woodborer, Phoracantha semipunctata, to host plant in a wind tunnel. Physiological Entomology, 26, 26-37.

Bartelt, R.J., Dowd, P.F., Shorey, H.H. \& Weisleder, D. (1990) Aggregation pheromone of dried-fruit beetle, Carpophilus hemipterus: wind-tunnel bioassay and identification of two novel tetraene hydrocarbons. Journal of Chemical Ecology, 16, 1015-1039.

Batschelet, E. (1981) Circular Statistics in Biology. Academic Press, New York, New York.

Cardé, R.T. \& Hagaman, T.E. (1979) Behavioral responses of the gypsy moth in a wind tunnel to air-borne enantiomers of disparlure. Environmental Entomology, 8, 475-484.

Charlton, R.E., Kanno, H., Collins, R.D. \& Cardé, R.T. (1993) Influence of pheromone concentration and ambient temperature on flight of the gypsy moth, Lymantria dispar, in a sustained flight wind tunnel. Physiological Entomology, 18, 349-362.

Choudhury, J.H. \& Kennedy, J.S. (1980) Light versus pheromonebearing wind in the control of flight direction by bark beetles, Scolytus multistriatus. Physiological Entomology, 5, 207-214.

Cork, A., Hall, D.R., Hodges, R.J. \& Pickett, J.A. (1991) Identification of major component of the male produced aggregation pheromone of the larger grain borer, Prostephanus 
truncatus (Horn) (Coleoptera: Bostrichidae). Journal of Chemical Ecology, 17, 789-803.

David, C.T. (1978) The relationship between body angle and flight speed in free-flying Drosophila. Physiological Entomology, 3, 191-195.

Fadamiro, H.Y. (1995) Flight behaviour and pheromone communication of the larger grain borer Prostephanus truncatus (Horn) (Coleoptera: Bostrichidae). D.Phil. Thesis, University of Oxford, U.K.

Fadamiro, H.Y. (1996) Influence of stimulus dose and wind speed on the orientation behaviour of Prostephanus truncatus (Coleoptera: Bostrichidae) to pheromone. Bulletin of Entomological Research, 86, 659-665.

Fadamiro, H.Y. (1997) Free flight capacity determination in a sustained flight tunnel: effects of age and sexual state on the flight duration of Prostephanus truncatus. Physiological Entomology, 22, 29-36.

Fadamiro, H.Y. \& Wyatt, T.D. (1995) Flight initiation by Prostephanus truncatus in relation to time of day, temperature, relative humidity, and starvation. Entomologia Experimentalis et Applicata, 75, 273-277.

Food and Agriculture Organization (1970) The State of Food and Agriculture. FAO, Italy.

Haynes, K.F. \& Baker, T.C. (1989) An analysis of anemotactic flight in female moths stimulated by host odour and comparison with the males' response to sex pheromone. Physiological Entomology, 14, 279-289.

Heath, R.R. \& Manukian, A. (1992) Development and evaluation of systems to collect volatile semiochemicals from insects and plants using a charcoal-infused medium for air purification. Journal of Chemical Ecology, 18, 1209-1226.

Kennedy, J.S. (1940) The visual responses of flying mosquitoes. Proceedings of the Zoological Society of London A, 109, 221-242.

Kennedy, J.S. (1983) Zigzagging and casting as a programmed response to wind-borne odour: a review. Physiological Entomology, 8, 109-120.

Kuenen, L.P.S. \& Baker, T.C. (1982) The effects of pheromone concentration on the flight behaviour of the oriental fruit moth. Physiological Entomology, 7, 423-434.

Kuenen, L.P.S. \& Cardé, R.T. (1993) Effects of moth size on velocity and steering during upwind flight toward a sex pheromone source by Lymantria dispar (Lepidoptera: Lymantriidae). Journal of Insect Behavior, 6, 177-193.

Kuenen, L.P.S. \& Cardé, R.T. (1994) Strategies for recontacting a lost pheromone plume: casting and upwind flight in the male gypsy moth. Physiological Entomology, 19, 15-29.

Kuenen, L.P.S., Wagner, D.L., Wallner, W.E. \& Cardé, R.T. (1994) Female sex pheromone in Korscheltellus gracilis (Lepidoptera: Hepialidae). Canadian Entomologist, 126, 31-41.

Lextrait, P., Biémont, J.C. \& Pouzat, J. (1994) Comparison of walking locomotory reactions of two forms of Callosobruchus maculatus males subjected to female sex pheromone stimulation
(Coleoptera: Bruchidae). Journal of Chemical Ecology, 20, 2917-2930.

Mafra-Neto, A. \& Cardé, R.T. (1994) Fine-scale structure of pheromone plumes modulates upwind orientation of flying moths. Nature, 369, 142-144.

Marsh, D., Kennedy, J.S. \& Ludlow, A.R. (1978) An analysis of anemotactic zigzagging flight in male moths stimulated by pheromone. Physiological Entomology, 3, 221-240.

Phillips, T.W., Phillips, J.K., Webster, F.X. et al. (1996) Identification of sex pheromones from the cowpea weevil Callosobruchus maculatus, and related studies with $C$. analis (Coleoptera: Bruchidae). Journal of Chemical Ecology, 22, 2233-2249.

Raina, A.K. (1970) Callosobruchus spp. infesting stored pulses (grain legumes) in India and a comparative study of their biology. Indian Journal of Entomology, 32, 303-310.

SAS (2001) SAS/STAT User's Guide, Version 6, 4th edn. SAS Institute, Inc., Cary, North Carolina.

Shu, S.-Q., Koepnick, W.L., Mbata, G.N. et al. (1996) Sex pheromone production in Callosobruchus maculatus (Coleoptera: Bruchidae): electroantennographic and behavioral responses. Journal of Stored Product Research, 12, 21-30.

Sokal, R.R. \& Rohlf, F.J. (1981) Biometry, 2nd edn. WH Freeman, New York, New York.

Vickers, N.J. \& Baker, T.C. (1997) Flight of Heliothis virescens males in the field in response to sex pheromone. Physiological Entomology, 22, 277-285.

Williams, H.J., Silverstein, R.M., Burkholder, W.E. \& Khorramshahi, A. (1981) DOMINICALURE 1 and 2: components of Aggregation pheromone from male lesser grain borer. Rhyzopertha dominica (F.) (Coleoptera: Bostrichidae). Journal of Chemical Ecology, 7, 759-780.

Willis, M.A. \& Arbas, E.A. (1991) Odor-modulated upwind flight of the sphinx moth, Manduca sexta L. Journal of Comparative Physiology A, 169, 427-440.

Willis, M.A. \& Arbas, E.A. (1998) Variability in odor-modulated flight by moths. Journal of Comparative Physiology A, 182, 191-202.

Willis, M.A. \& Baker, T.C. (1987) Comparison of manoeuvres used by walking versus flying Grapholita molesta males during pheromone-mediated upwind movement. Journal of Insect Physiology, 33, 875-883.

Willis, M.A. \& Cardé, R.T. (1990) Pheromone-modulated optomotor response in male gypsy moths, Lymantria dispar (L.) upwind flight in a pheromone plume in different wind velocities. Journal of Comparative Physiology A, 167, 699-706.

Young, S., David, C.T. \& Gibson, G. (1987) Light measurement for entomology in the field and laboratory. Physiological Entomology, 12, 373-379.

Accepted 2 September 2005

First published online 6 January 2006 